\section{Curcumin as an anti-human papillomavirus and anti-cancer compound}
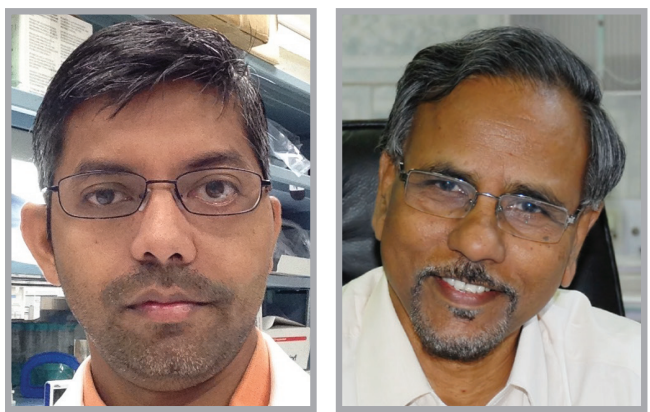

“...it appears that ... curcumin may serve as a strong antihuman papillomavirus agent, which can be used, to either prevent human papillomavirus infection or facilitate the effective treatment of cervical or oral cancer...”
Alok Mishra*1,2 \& Bhudev C Das ${ }^{* * 1,2,3}$

More than four decades ago, the link between human papillomavirus (HPV) infection and cervical cancer was proposed by a German physician-scientist Harald zur Hausen [1]. His group started working on HPV in early 1970s and isolated two most oncogenic high-risk strains, HPV type 16 and HPV 18, after almost a decade later [2]. Several clinico-epidemiological and molecular studies finally established the causative link between HPV infection and cervical cancer. This seminal work earned zur Hausen a Nobel Prize for medicine in 2008. Several studies later showed that HPV infections constitute about 5\% of global burden of human cancers [3].

HPV is a small $(\sim 8 \mathrm{~kb})$ DNA tumor virus which has been shown to be prevalent in about $90 \%$ of cervical cancers, $90 \%$ of anal cancers, $50 \%$ of penile, $40 \%$ of vulvar, $70 \%$ of vaginal cancers and $20-60 \%$ of cancers of the oropharynx [4]. High-risk (HR) HPV types 16 and 18 are specifically implicated in $80-90 \%$ of cervical cancers and $30-70 \%$ in cancers of other anatomical sites [5]. Interestingly, HPV-related oropharyngeal and/or head and neck cancers are increasing with alarming rate among men and women in developing countries.

To date, there is no specific therapy for effective treatment of HPV. However, recently developed virus-like particle (the major HPV virion protein L1) based two prophylactic vaccines - quadrivalent Gardasil (HPV 16/18/6/11) and bivalent Cervarix (HPV 16/18) are commercialized around the world [6,7]. In 2014, the US FDA further approved a nonavalent vaccine against nine HPV types (HPV 6, $11,16,18,31,33,45,52$ and 58) [8], but these vaccines are still not all-over available in India and other developing countries.

This article is an attempt to briefly discuss the antiviral/anticancer activity of curcumin during HPV-mediated carcinogenesis. We limit the scope of this article mainly to oral and cervical cancer in which infection of HPV is considered a major etiological factor. The expression of two viral oncogenes E6 and E7 that interacts with and degrade p53 and Rb, respectively, is essential for tumorigenic transformation and is dependent on the availability of a cellular transcription

\section{KEYWORDS}

- AP-1 - cervical cancer • curcumin

- HPV • NF- $\kappa B$ • oral cancer

“...human papillomavirus-related oropharyngeal and/or head and neck cancers are increasing with alarming rate among men and women in developing countries."

IInstitute of Cytology \& Preventive Oncology, I-7, Sector -39, Noida, Uttar Pradesh 201301, India

${ }^{2}$ Ambedkar Centre for Biomedical Research, University of Delhi, Delhi-110 007, India

${ }^{3}$ Amity Institute of Molecular Medicine \& Stem Cell Research, Amity University, Noida, Uttar Pradesh 201313, India 


\section{“Besides [curcumin's] use as a spice, it has innumerable health effects and exhibited pleotropic roles as antiviral, anticancer, anti-inflammatory and wound healing agent.”}

factor AP-1 derived from the host cell [9]. We have demonstrated that transactivation and DNA-binding activity of cellular transcription factor AP-1 and the proinflammatory transcription factor NF- $\kappa \mathrm{B}$ can be modulated by alterations of the intracellular redox status by synthetic antioxidative agent pyrrolidine dithiocarbamate [10], leading to selective suppression of transcription of HPV in cervical cancer cells. We, therefore, thought it would be highly interesting to investigate in cervical and oral cancer the role of a potent natural antioxidant - curcumin, which is being used in Indian system of traditional medicine for a myriad of effects and remedies since time immemorial.

Curcumin (diferulolylmethane, 1,7 (4-OH-3 methoxy phenyl) 1-6, heptadene 3,5-dione), an active ingredient of Indian spice is derived from a perennial herb turmeric Curcuma longa of the Zingiberaceae (ginger) family and used extensively for cooking in southeast Asian region. It contains a class of compounds known as curcuminoids, comprising curcumin (77\%), demethoxycurcumin (17\%) and bisdemethoxycurcumin $(3 \%)$, among which curcumin is the

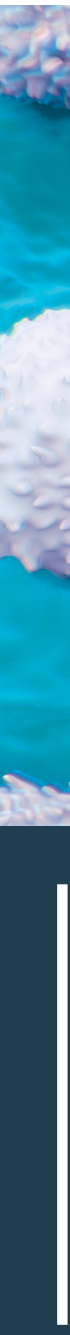

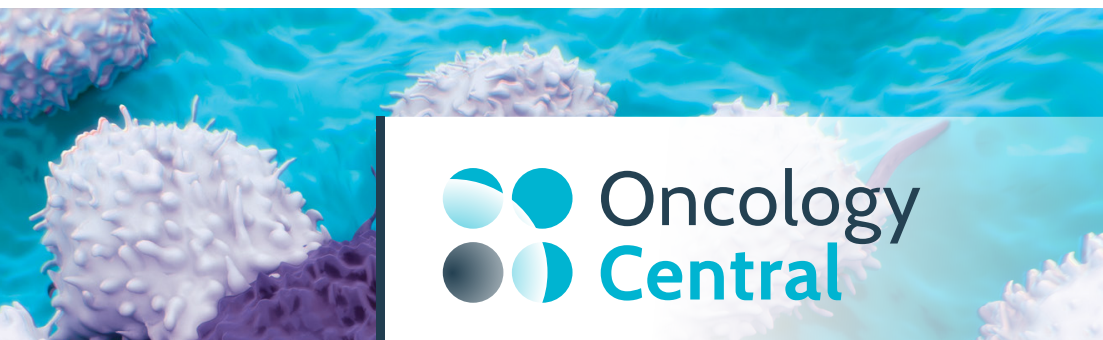

. . . . . Prese

\section{ADVANCING ONCOLOGY TOGETHER}

Find out how; join our online community today main molecule accounting for approximately $2-5 \%$ of turmeric powder [11]. Besides its use as a spice, it has innumerable health effects and exhibited pleotropic roles as antiviral, anticancer, anti-inflammatory and wound healing agent. As a dietary supplement, it has been shown to be a pharmacologically safe compound with a very low or no toxicity and the doses as high as $8 \mathrm{~g} /$ day have been administered orally to humans with no side effects [11,12].

Curcumin suppresses numerous regulatory molecules and signaling pathways that are invariably upregulated in cancers and other diseases, thus making it an excellent chemopreventive as well as chemosensitizing agent. Curcumin can suppress cell growth and tumor formation by downregulating critical kinases such as PKC, JNK, EGFR and MAPK etc. [13]. It also inhibits NF- $\mathrm{KB}, \mathrm{AP}-1$ pathways including cyclin D1 and inflammatory cytokines and chemokines [14]. Curcumin induces expression of phase II metabolizing enzymes and antiangiogenic effects by inhibiting CYP450, VEGF receptor and angiopoietin, respectively. Curcumin is known to induce apoptosis by activating mitochondrial pathways leading to activation of caspase 3, 7 and 9 and cleavage of PARP and inhibits antiapoptotic genes $\mathrm{Bcl} 2$ and $\mathrm{BclxL}$ (reviewed by Bharti et al.) [11].

In our in vitro studies in cervical and oral cancer cells, curcumin has shown to have a strong anti-HPV effect $[15,16]$. Based on these preclinical studies, we also carried out a placebo controlled, double-blind, randomized Phase II clinical trial of curcumin and its other formulation 'Basant' [17]. Yet another clinical trials study on intravaginal application of curcuminbased capsule or vaginal cream at bed time for 4 weeks has shown remarkable $(\sim 80 \%)$ clearance of the virus $[18,19]$. Several other authors have also reported the role of curcumin as an anti-HPV agent. Curcumin treatment, shown to inhibit transcription of HPV 16 E6/E7 as early as $6 \mathrm{~h}$ post-treatment, restores the expression of tumor suppressor proteins $\mathrm{p} 53, \mathrm{Rb}$ and PTPN13 [20]. It has the ability to improve the paclitaxel-induced apoptosis of HPV-positive human cervical cancer cell lines via the NF- $\kappa B$, p53-caspase 3 pathway [21]. Curcumin also promotes histone deacetylation, remodels chromatin and p53-mediated proapoptotic transactivation [22]. The protein-ligand based analysis has shown that interaction of curcumin at the p53-binding pocket of E6 protein residues 
113-122 (CQKPLCPEEK) facilitates restoration of p53 function [23]. Curcumin reported to increase the radiation sensitivity of head and neck cancer cells via inhibition of thioredoxin reductase 1 [24]. Thus, this herbal antioxidant can suppress HPV oncoproteins, restores p53, $\mathrm{rb}$, and ptpn 13 proteins and inhibits tobacco carcinogen benzo[a]pyrene-induced upregulation of HPV E7. Curcumin is also known to downregulate increased expression of miRNA-21 in cervical cancer via AP-1 that binds to its promoter [25].

Although curcumin has the potential to downregulate HPV oncogene expression and may serve as potential therapeutic agent for HPV-induced cancers, but hydrophobicity, rapid metabolism, off targeting and poor bioavailability are some of its major problems. Therefore, many curcumin derivatives, nanocurcumins or specific chemical moieties are attached to curcumin to circumvent these problems [26]. We have recently developed a low-molecular weight curcumin-2Folic acid (cur-2FA) conjugate for targeted delivery of curcumin to cancer cells or cancer stem cells that selectively overexpress high-affinity folate receptor on their cell surface. We have shown enhanced cellular uptake of Cur-2FA and increased bioavailability. The conjugation chemistry is used in such a way that Cur-2FA becomes water soluble, and it has been demonstrated that curcumin can make cancer as well as cancer stem cells highly sensitive to chemoradiotherapy by inhibiting ATPbinding cassette protein ABCG2, thus making the cancer treatment most effective [DAS BC ET AL., Unpublished Data].

In the light of available studies and data, it appears that this natural herbal antioxidant curcumin may serve as a strong anti-HPV agent, which can be used, to either prevent HPV infection or facilitate the effective treatment of cervical or oral cancer by targeting and sensitizing cancer and cancer stem cells.

\section{Disclaimer}

The content does not represent the official views of the Indian Council of Medical research.

\section{Financial \& competing interests disclosure}

The project described was supported by Indian Council of Medical Research, Department of Biotechnology and Council for Scientific and Industrial Research, India grants. The authors have no other relevant affliations or financial involvement with any organization or entity with a financial interest in or financial conflict with the subject matter or materials discussed in the manuscript apart from those disclosed.

No writing assistance was utilized in the production of this manuscript.

\section{References}

1 Hausen H zur. Papillomaviruses in the causation of human cancers - a brief historical account. Virology 384, 260-265 (2009).

2 Gissmann L, zur Hausen H. Partial characterization of viral DNA from human genital warts (condylomata acuminate). Int. J. Cancer 25, 605-609 (1980).

3 Oh JK, Weiderpass E. Infection and cancer: global distribution and burden of diseases. Ann. Glob. Health 80, 384-392 (2014).

4 Herrero R, González P, Markowitz LE. Present status of human papillomavirus vaccine development and implementation. Lancet Oncol. 2045, 70481-70484 (2015).

5 Das BC, Hussain S, Nasare V, Bharadwaj M. Prospects and prejudices of human papillomavirus vaccines in India. Vaccine 26, 2669-2679 (2008).

6 Villa LL, Costa RL, Pettac A et al. Prophylactic quadrivalent human papillomavirus (types $6,11,16$, and 18) L1 virus-like particle vaccine in young women: a randomized double-blind placebo- controlled multicentre Phase II efficacy trial. Lancet Oncol. 6, 271-278 (2005).

7 Harper DM, Franco EL, Wheeler C et al. Efficacy of a bivalent L1 virus-like particle vaccine in prevention of infection with human papillomavirus types 16 and 18 in young women: a randomized controlled trial. Lancet 364, 1757-1765 (2004).

Pils S, Joura EA. From the monovalent to the nine-valent HPV vaccine. Clin. Microbiol. Infect. doi:10.1016/j.cmi.2015.05.001 (2015) (Epub ahead of print).

9 zur Hausen H. Papillomaviruses and cancer: from basic studies to clinical application. Nat. Rev. Cancer 2, 342-350 (2002).

10 Rosl F, Das BC, Lengert M, Geletneky K, zur Hausen H. Antioxidant-induced changes of the AP-1 transcription complex are paralleled by a selective suppression of human papillomavirus transcription. J. Virol. 71, 362-370. (1997).

11 Aggarwal BB, Kumar A, Bharti AC. Anticancer potential of curcumin: preclinical and clinical studies. Anticancer Res. 23, 363-398 (2003).
12 Sharma RA, Euden SA, Platton SL et al. Phase I clinical trial of oral curcumin: biomarkers of systemic activity and compliance. Clin. Cancer Res. 10, 6847-6854 (2004).

13 Dorai T. Therapeutic potential of curcumin in human prostate cancer. II. Curcumin inhibits tyrosine kinase activity of epidermal growth factor receptor and depletes the protein. Mol. Urol. 4, 1-6. (2000).

14 Han SS, Keum YS, Seo HJ, Surh YJ. Curcumin suppresses activation of $\mathrm{NF}-\kappa \mathrm{B}$, and AP-1 induced by phorbol ester in cultured human promyelocytic leukemia cells. J. Biochem. Mol. Biol. 35, 337-342 (2002).

15 Prusty BK, Das BC. Constitutive activation of transcription factor AP-1 in cervical cancer and suppression of human papillomavirus (HPV) transcription and AP-1 activity in HeLa cells by curcumin. Int. J. Cancer 113, 951-960 (2005).

16 Mishra A, Kumar R, Kohaar I et al. Curcumin modulates cellular AP-1, NF-kB, and HPV16 E6 proteins in oral cancer. Ecancermedicalscience 9, 525 (2015). 
17 Basu P, Dutta S, Begum R et al. Clearance of cervical human papillomavirus infection by topical application of curcumin and curcumin containing polyherbal cream: a Phase II randomized controlled study. Asian Pac. J. Cancer Prev. 14, 5753-5759 (2013).

18 Debata PR, Castellanos MR, Fata JE et al. A novel curcumin-based vaginal cream Vacurin selectively eliminates apposed human cervical cancer cells. Gynecol. Oncol. 129, 145-153 (2013).

19 Talwar GP, Dar SA, Rai MK et al. A novel polyhedral microbicide with inhibitory effect on bacterial, fungal and viral genital pathogens. Int. J. Antimicrob. Agents 32, 180-185 (2008).

20 Maher DM, Bell MC, O’Donnell EA, Gupta BK, Jaggi M, Chauhan SC. Curcumin suppresses human papillomavirus oncoproteins, restores $\mathrm{p} 53, \mathrm{Rb}$, and PTPN13 proteins and inhibits benzo [a] pyreneinduced up regulation of HPV E7. Mol. Carcinog. 50, 47-57 (2011).

21 Dang YP, Yuan XY, Tian R, Li DG, Liu W. Curcumin improves the paclitaxel-induced apoptosis of HPV-positive human cervical cancer cells via the NF- $\kappa \mathrm{B}-\mathrm{p} 53$-caspase-3 pathway. Ther. Med. 9, 1470-1476 (2015).

22 Chakraborty S, Das K, Saha S et al. Nuclear matrix protein SMAR1 represses c-Fosmediated HPV18 E6 transcription through alteration of chromatin histone deacetylation. J. Biol. Chem. 42, 29074-29085 (2014).

23 Kumar S, Jena L, Galande S, Daf S, Mohod $\mathrm{K}$, Varma AK. Elucidating molecular interactions of natural inhibitors with HPV-16
E6 oncoprotein through docking analysis. Genomics Inform. 12, 654-670 (2014).

24 Tuttle S, Hertan L, Daurio N et al. The chemopreventive and clinically used agent curcumin sensitizes HPV (-) but not HPV (+) HNSCC to ionizing radiation, in vitro and in a mouse orthotropic model. Cancer Biol. Ther. 13, 575-584 (2012).

25 Mudduluru G, George-William JN, Muppala S. Curcumin regulates miR-21 expression and inhibits invasion and metastasis in colorectal cancer. Biosci. Rep. 31, 185-197 (2011).

26 Prasad S, Tyagi AK, Aggarwal BB. Recent developments in delivery, bioavailability, absorption and metabolism of curcumin: the golden pigment from golden spice. Cancer Res. Treat. 46, 2-18 (2014). 